\title{
MASSA DA PROMESSA UMA MANIFESTAÇÃO DE FÉ DA COMUNIDADE LOCAL
}

\author{
Anita de Gusmão Ronchetti (UFSC) \\ Nicole Pelaez (IFSC) \\ Silvana Graudenz Müller (IFSC)
}

O presente artigo apresenta um histórico da massa da promessa produzida nas festas do Divino Espírito Santo em Florianópolis e descreve a trajetória de transformação, apontando sua importância como manifestação cultural de cunho religioso para a comunidade. Foram realizadas pesquisas bibliográfica e documental, bem como de campo, utilizando-se ferramenta como entrevista semiestruturada e observação da produção com registro fotográfico. Constatou-se que essa tradição vem diminuindo, o que pode levar à extinção da prática.

\section{MASSA DA PROMESSA; IDENTIDADE CULTURAL;} GASTRONOMIA LOCAL.

RONCHETTI, Anita de Gusmão; PELAEZ, Nicole; MÜLLER, Silvana Graudenz. Massa da promessa: uma manifestação de fé da comunidade local. Textos escolhidos de cultura e arte populares, Rio de Janeiro, v.12, n.1, p. 61-71, mai. 2015. 


\section{THE BREAD OF PROMISSE}

A MANIFESTATION OF FAITH OF A LOCAL COMMUNITY

Anita de Gusmão Ronchetti (UFSC)

Nicole Pelaez (IFSC)

Silvana Graudenz Müller (IFSC)

This article presents a history of the bread of promise produced in the Holy Spirit parties in Florianopolis and describes the path of transformation, pointing to its importance as a cultural manifestation of religious significance to the community. Bibliographical, documentary and field research surveys were conducted, using tools such as semi-structured interviews and observation of production with photographic registry, discovering that this tradition is waning and may lead to the extinction of the practice.

BREAD OF PROMISE; CULTURAL IDENTITY; LOCAL CUISINE.

RONCHETTI, Anita de Gusmão; PELAEZ, Nicole; MÜLLER, Silvana Graudenz. Massa da promessa: uma manifestação de fé da comunidade local. Textos escolhidos de cultura e arte populares, Rio de Janeiro, v.12, n.1, p. 61-71, mai. 2015. 


\section{O PÃO E SEUS SIGNIFICADOS SAGRADOS}

A massa da promessa é o nome atribuído ao pão que reflete a tradição de fé e está presente durante o ciclo de festa do Divino Espírito Santo no litoral de Santa Catarina. Esse pão é um ex-voto que representa a devoção ao Espírito Santo, como pagamento de uma promessa de fé referente a questões de saúde cuja graça foi alcançada. É modelado em forma de partes do corpo como braços, pernas, bonecos inteiros, de acordo com o segmento corporal que deu motivo à promessa.

O pão, em geral, está presente em praticamente toda a história da humanidade; Braga (2006) comenta a existência desse alimento há cerca de seis mil anos antes de Cristo. Primeiro, o homem prepara com os grãos uma pasta crua, que posteriormente passa a assar sobre pedras quentes e chega até a utilização de fornos ainda na Antiguidade.

Para a Igreja católica o pão é alimento sagrado, presente desde o Antigo Testamento e que representa o corpo de Jesus Cristo, símbolo da comunhão cristã. Durante a Idade Média, houve um período de escassez no cultivo dos grãos em virtude do processo de urbanização, diminuindo assim a produção de farinhas e de pães. Com incentivo da Igreja católica, porém, o cultivo dos grãos foi recuperado.

Ribeiro (2012) assim justifica a importância do pão para a Igreja católica: “O pão não só constitui o alimento comum a grande parte da humanidade, como também pode ser encontrado em toda a parte do mundo, nas mais diversas formas e receitas. Esse fato foi de extrema importância para o seu uso pelo cristianismo." Outras religiões também consideram o pão sagrado. No judaísmo, por exemplo, o challah é um pão tradicional trançado e compartilhado durante o Shabbat. Em Israel é trançado e modelado em forma de rosca, "simbolizando a roda da vida" (BRAGA, 2006).

A massa da promessa é atributo religioso bastante significativo e de muita devoção na festa do Divino Espírito Santo em Florianópolis (SC) e região em seu entorno, porém, tanto a receita original quanto os saberes e fazeres que definem a produção, bem como o significado religioso desse pão para a comunidade, que integra seu patrimônio imaterial, estão se perdendo por falta de registros e de planos de salvaguarda desse conhecimento.

Com vistas a fundamentar a importância da preservação dessa manifestação religiosa, que utiliza a gastronomia como instrumento, este artigo tem como objetivo apresentar um histórico da festa do Divino Espírito Santo e do 
pão nesse contexto, sua produção e as transformações ocorridas com a massa da promessa.

Para a coleta dos dados primários as pesquisadoras estiveram presentes nas festas do ciclo 2013-2014, em Florianópolis, utilizaram métodos como entrevistas semiestruturadas feitas com a comunidade presente, observação, e registro fotográfico, complementando a pesquisa com a observação participante da produção da massa. Para coletar os dados secundários foram realizadas pesquisas bibliográfica e documental.

\section{A FESTA DO DIVINO ESPÍRITO SANTO}

A festa do Divino teve sua origem em Portugal, por volta do século XIII, através de celebrações inicialmente no formato de banquetes religiosos e coletivos com distribuição de comida e esmola para a população mais carente. Desde então essa devoção portuguesa tem-se perpetuado através da história, desde Açores até os redutos de imigração no Novo Mundo, como Brasil, Estados Unidos e Canadá, representando a maior referência identitária da presença açoriana em qualquer parte do mundo (NUNES, 2010).

Para referir-se a esse culto religioso no Brasil, é preciso voltar ao passado, com a chegada dos primeiros imigrantes açorianos no século XVIII para colonizar a Ilha de Santa Catarina (FARIAS, 2000), trazendo consigo a devoção religiosa como marca mais expressiva da cultura portuguesa.

A celebração do Divino Espírito Santo é tradição secular que ainda hoje é observada na maioria dos municípios litorâneos de imigração açoriana. Popularmente conhecida como culto ao Divino, essa festa exterioriza a devoção à Terceira Pessoa da Santíssima Trindade, ou seja, o Espírito Santo, por meio de ritual religioso que envolve tradição, significados, crenças e simbologias da identidade cultural religiosa e popular (ROSA, 1999).

A essência dessa festa portuguesa baseava-se na fraternidade e igualdade de todos, representada pelos "bodos", que significavam a distribuição de comida, como pão, carne, vinhos e, em especial, a sopa do Divino Espírito Santo(ROSA, 1999). No Estado de Santa Catarina, entretanto, essa tradição se perdeu completamente ao longo dos anos (FARIAS, 2000).

Com o compromisso de organizar as festas e resguardar o culto, surgem as Irmandades ou confrarias do Espírito Santo tendo como responsabilidade contribuir para o estabelecimento do "império da igualdade" (SANTOS, 1998). A principal irmandade responsabilizada pela organização dessa festa no Centro da cidade 
de Florianópolis foi fundada entre 1773 (FARIAS, 2000; NUNES, 1999) ou 1774 (PEREIRA, 1999) e ainda hoje é conhecida como Irmandade do Divino Espírito Santo.

O ritual do pagamento de promessas pode ser considerado uma das características marcantes dessa festividade, que tem como marca a representação dos compromissos assumidos pelos fiéis, em troca de alguma graça alcançada, paga por quem foi favorecido ou em seu nome. Diversos tipos de promessas eram praticados em especial as massas para arremates.

Quando alguém tinha problemas de saúde (braço quebrado ou dores no corpo) era feita uma massa muito gostosa, com o formato da parte doente do corpo. Essa massa era leiloada em novenas da Igreja e o dinheiro era doado para o Santo. O ganhador mandava entregar a massa a alguém de quem gostasse esse por sua vez comia a massa durante a festa (FARIAS, 2000, p. 434).

Conforme dados coletados na pesquisa de campo, o início do ritual de preparo da massa de pão foi um incentivo da Igreja, já que os fiéis, muitas vezes, não conseguiam pagar pelas promessas com outros bens materiais.

\section{A MASSA DA PROMESSA E A FESTA DO DIVINO ESPÍRITO SANTO}

A presença da colonização açoriana em Florianópolis ficou marcada pela forte religiosidade que circundava a colônia de Nossa Senhora do Desterro, atual Florianópolis. As festas religiosas sempre foram bastante frequentes, envolvendo intimamente a cultura regional dessa localidade através de diferentes tradições simbólicas, observadas principalmente por meio da gastronomia.

Observou-se durante a festa que essa representatividade é ainda presente. Pessoas da comunidade costumam comprar o pão por diversos motivos: para ajudar a Igreja, como pagamento de promessa, como agradecimento ou até por costume, sem motivo específico. Porém, alguns turistas e até mesmo moradores da cidade desconhecem o significado dessa massa para a festa.

Durante o ciclo da festa, a massa da promessa estava presente nas localidades do Centro, Trindade, Campeche, Santo Antônio de Lisboa e Ribeirão da Ilha. Apesar disso, há pouco destaque para o produto durante a festa, limitando sua importância às pessoas que já o conhecem. A festa do Centro de Florianópolis foi o local de maior destaque para o pão, que estava presente em grande quantidade e diferentes formatos. Além disso, havia materiais midiáticos informativos relacionados à massa (Figura 1 ).

Na maioria das localidades em que havia o pão de promessa, ele foi exposto e comercializado em algum local especial da festa, em que as pessoas compra- 


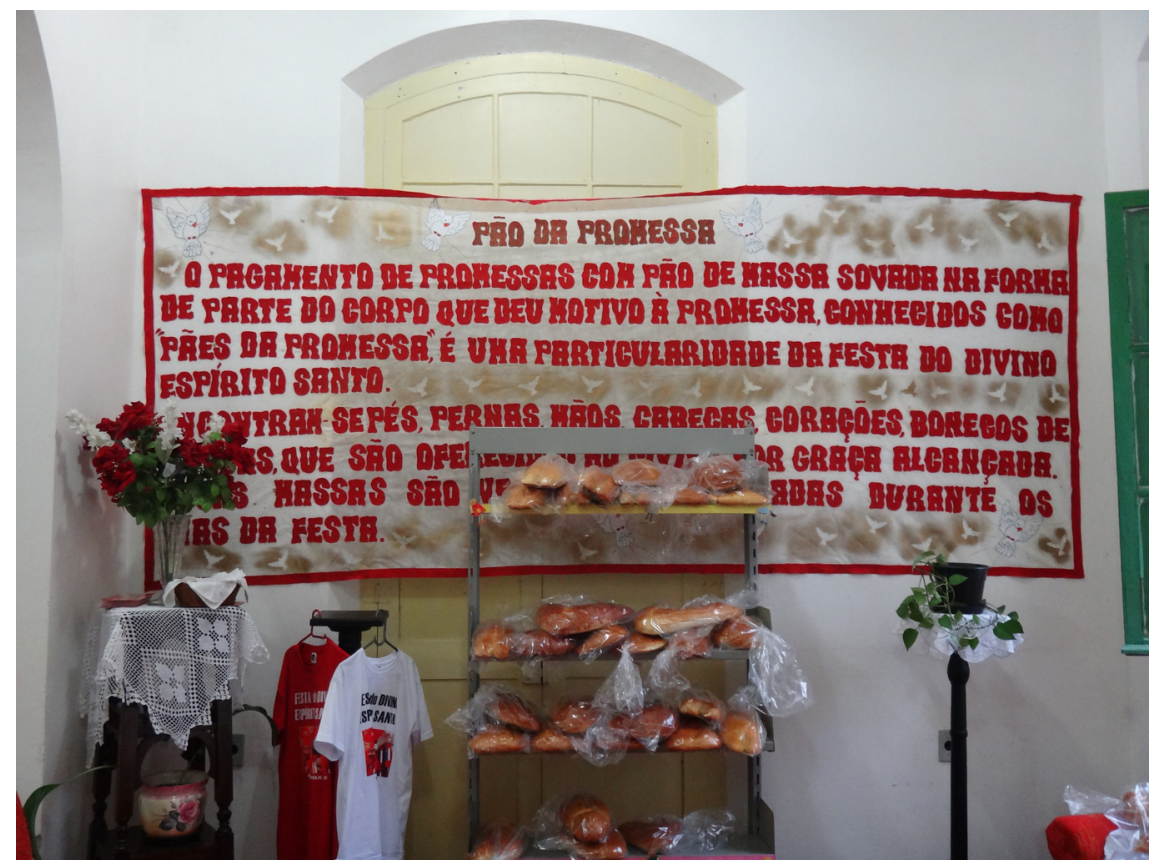

Figura 1: Local de venda da massa da promessa na festa do Centro de Florianópolis Foto: Anita de Gusmão Ronchetti

vam seu pão e o deixavam sobre o altar como pagamento de promessa ou o levavam para casa a fim de compartilhar com os familiares. Mas houve exceção em uma localidade: havia no altar apenas um pão a ser leiloado durante a festa.

\section{AS TRANSFORMAÇÕES DOS SABERES E DOS SABORES}

As pessoas entrevistadas durante a festa não conheciam a receita da massa e nem alguém que pudesse conhecer, porém, a maioria delas confirmou sempre comprar a massa pronta, feita em padaria. Parte dos entrevistados comprava a massa como pagamento de promessa, parte com outros fins religiosos, parte como forma de ajudar a Igreja e parte comprava sem saber o motivo e sem conhecer a história da massa.

Com relação ao sabor, todos os entrevistados admitiram gostar da massa, mas alguns ressaltaram que antigamente a massa era mais gostosa, sugerindo que realmente houve modificação na receita e no modo de preparo do pão.

Quanto à preservação dos conhecimentos referentes à massa da promessa, todos os entrevistados acharam importante preservar essa cultura. 
As modificações feitas na massa da promessa já descaracterizaram o pão original, causando perda dos saberes e fazeres, e consequentemente dispersão do conhecimento como forma de manutenção da identidade cultural.

D’Ávila (1999) comenta a elaboração e os ingredientes da massa da promessa:

Na maioria das vezes, da feitura da massa se encarrega a mulher, mas há quem a encomende ao padeiro. Os ingredientes, segundo uma receita recolhida em Limeira, interior do Município de Camboriú, em 1995, são um ovo, meia xícara de açúcar, uma colher de manteiga, uma colher de banha de porco, uma colher de fermento de pão, meia xícara de água morna e farinha de trigo. Então, juntam-se os ingredientes, acrescentando a farinha de trigo até a massa adquirir consistência. A seguir, ela deve ser bem sovada. Depois estica-se a massa com o rolo de macarrão e faz-se com a faca o recorte da figura conforme a promessa: uma cabeça, um braço, uma mão, dois olhos, uma perna, um pé, a figura inteira de uma pessoa ou de um animal. Deixa-se crescer a massa e, então, leva-se ao forno para cozer.

Nunes (2010), comenta que na Enseada do Brito não se admitem massas produzidas em panificadoras. Elas são caseiras e feitas em forno a lenha, sob encomenda. ${ }^{1}$

Atualmente, apenas dois estabelecimentos comerciais localizados em Florianópolis são responsáveis pela produção dessas massas. Pode-se afirmar que esses estabelecimentos não utilizam receitas originais, indicando perda significativa dos saberes e fazeres dessa produção.

De acordo com relatos de imigrantes açorianos, da receita mais antiga constava a utilização do fermento natural, sendo a batata, fonte de microrganismos, além da utilização de água, farinha de trigo e banha de porco. Além disso, a quantidade de ovos na receita era bem farta, e a massa era aromatizada com erva-doce, o que muito a diferenciava das receitas hoje produzidas em Florianópolis.

Atualmente os pães das festas do Divino Espírito Santo de Florianópolis são feitos em padaria, seguindo receita comercial, com formulação básica de padaria (Gráfico 1).

Como indica o gráfico 1 não há adição de nenhum ingrediente aromatizante, e a quantidade de ovos é equilibrada, mas a gordura utilizada continua sendo a banha de porco. Segundo o padeiro responsável pela produção, essa receita é utilizada há pelo menos nove anos. 


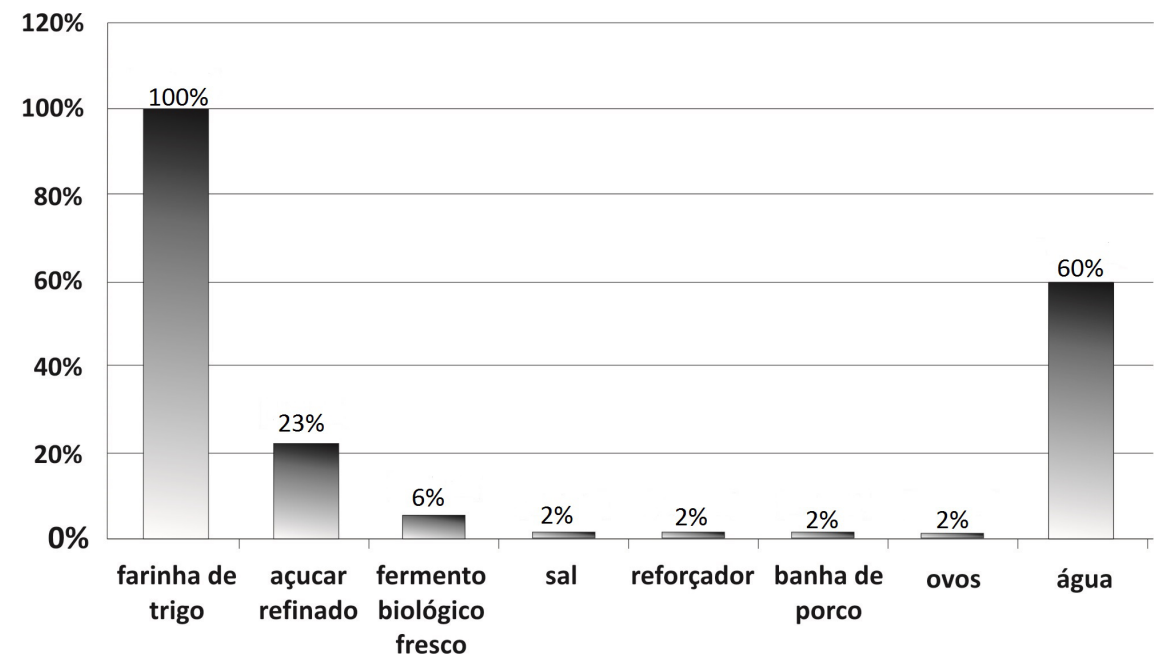

\section{Gráfico 1}

Cabral (1970) e Nunes (2010) relatam que durante essas festividades a massa da promessa era encontrada em formatos diversos, como mãos, pernas, pés, cabeças, braços e até seios (originando o pão de bico). Esses formatos continuam sendo produzidos pela padaria para as festas.

Várzea D'Ávila (apud D’ÁviLA, 1999) faz o registro da presença das massas de promessas durante a festa do Divino Espírito Santo nas comunidades de Santa Catarina durante o século XIX com formatos de "cabeças, pernas, braços, mãos, corpos inteiros de massas de pão; entregues pelas centenas de devotos; consumidas pelo povo sim, mas antes leiloadas" (Figura 2).

Desde 1994 essa festa acontece anualmente inserida em ciclo que tem início no Centro da cidade de Florianópolis em maio, especificamente na capela do Divino Espírito Santo, passa por vários bairros e se encerra em setembro, quando ocorre a última festa no bairro de Canasvieiras.

Essa festividade ainda hoje inclui danças, músicas, gastronomia, artesanato, lendas, crenças e superstições que consagram a identidade cultural religiosa portuguesa. Em algumas localidades, porém, notou-se a perda dessa identidade.

Desde o início do século XXI a massa da promessa vem desaparecendo das festas religiosas porque tanto o significado de fé quanto o processo produtivo de preparo da massa vêm sendo esquecidos com as facilidades de aquisição de novos produtos prontos e falta de interesse da atual geração. 


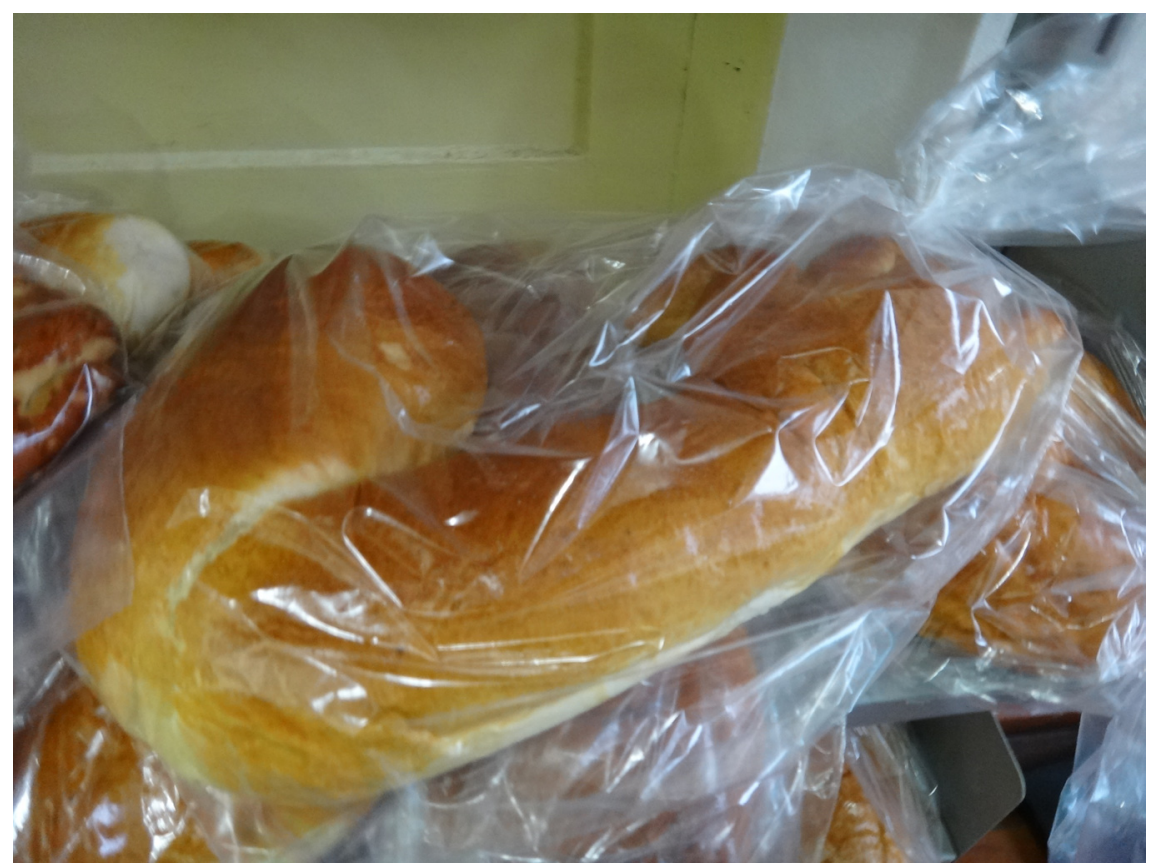

Figura 2: Massa da promessa em formato de braço Foto: Anita de Gusmão Ronchetti

\section{CONCLUSÃO}

A presença da colonização açoriana em Florianópolis ficou marcada por forte religiosidade. Um exemplo é o ciclo de festas do Divino Espírito Santo que ocorre todos os anos. A massa da promessa reflete a tradição de fé e está presente durante essa festa; trata-se de ex-voto que representa a devoção ao Espírito Santo, ofertado como pagamento de uma promessa de fé referente a questões de saúde em troca de graça que foi alcançada.

Os saberes e fazeres relacionados à produção desse pão estão, no entanto, se perdendo por falta de registros e de planos de salvaguarda desse conhecimento. A receita original já foi modificada, e em algumas festas durante o ciclo o pão nem foi encontrado. Nenhuma pessoa entrevistada possui os conhecimentos necessários para preparar o pão, apesar de reconhecer que o pão comercializado e ofertado atualmente é inferior, com relação ao sabor, ao de antigamente, ainda no século XX.

Os conhecimentos tradicionais relacionados à gastronomia fazem parte da identidade cultural dos povos e são considerados técnicas artesanais e práti- 
cas sociais, podendo ser reconhecidos como patrimônios imateriais e estão sendo valorizados a partir de ações de salvaguarda.

A festa do Divino Espírito Santo, bem como a massa da promessa e todo o seu contexto, representa a maior manifestação cultural e gastronômica da religiosidade e fé da comunidade local e constitui patrimônio imaterial, que merece ser conservado. Isso demonstra a importância da preservação dos conhecimentos tradicionais referentes ao pão e sua importância para a região. Uma forma de preservação é o registro e compartilhamento desses conhecimentos.

\section{NOTA}

1 As encomendas são feitas por dona Olinda e por dona Ceci. Massas sovadas e doces, para pagamento de promessas, sob a forma de uma parte do corpo humano ou em formato de animal (NUNES, 2010).

\section{REFERÊNCIAS BIBLIOGRÁFICAS}

BRAGA, P. Pão da paz: 195 receitas de pão de países-membros da ONU. São Paulo: Gaia; Boccato, 2006.

CABRAL, Rodrigues Oswaldo. Nossa Senhora do Desterro. v.1. Florianópolis: Lunardelli, 1970.

D’ÁVILA, Edson. A Festa do Divino Espírito Santo em Itajaí: invenção da tradição. Anais I Congresso Internacional das Festas do Divino Espírito Santo. Florianópolis: Ed. da UFSC, 1999.

FARIAS, Vilson Francisco de: De Portugal ao Sul do Brasil: 500 anos. Florianópolis: Ed. do autor, 2000.

NUNES, Lélia Pereira da Silva. Festa do Divino Espírito Santo - 250 anos depois. Anais I Congresso Internacional das Festas do Divino Espírito Santo. Florianópolis: Ed. ca UFSC, 1999.

Caminhos do Divino: um olhar sobre a festa do Espírito Santo em Santa Catarina. Florianópolis: Insular, 2010.

PEREIRA, Nereu do Vale. Notas sobre os Impérios do Divino na Açorianópolis. Anais I Congresso Internacional das Festas do Divino Espírito Santo. Florianópolis: Ed. da UFSC, 1999.

RIBEIRO, L.M.P. Análise antropológica dos símbolos da Igreja Presbiteriana do Brasil. Revista Ciências da Religião - História e Sociedade. v. 10, n. 2, 2012.

ROSA, Julio da. O culto do Espírito Santo na alma e na vida do povo açoriano. Anais I Congresso Internacional das Festas do Divino Espírito Santo. Florianópolis: Ed. da UFSC,1999. 
SANTOS, G. A. A festa do Divino Espírito Santo entre os açorianos de São Paulo. Travessia - Revista do Migrante, n. 31, p. 26-30, mai.-ago., 1998.

Anita de Gusmão Ronchetti é tecnóloga em gastronomia, mestranda em engenharia e gestão do conhecimento pela Universidade Federal de Santa Catarina e professora na área de gastronomia do Instituto Federal de Santa Catarina.

Nicole Pelaez é mestre em turismo e hotelaria pela Universidade do Vale do Itajaí e professora efetiva na área de gastronomia do Instituto Federal de Santa Catarina.

Silvana Graudenz Müller é doutora em engenharia e gestão do conhecimento pela Universidade Federal de Santa Catarina, professora e pesquisadora de gastronomia brasileira do Instituto Federal de Educação, Ciência e Tecnologia de Santa Catarina.

Recebido em: 14/07/2014

Aceito em: 03/09/2014 
